\title{
Rhodium(I)-Catalyzed Carbonylative Arylation of Alkynes with Arylboronic Acids Using Formaldehyde as a Carbonyl Source
}

\author{
Chuang Wang, ${ }^{\text {a }}$ Tsumoru Morimoto, ${ }^{* a}$ Hiroyuki Kanashiro, ${ }^{a}$ Hiroki Tanimoto, ${ }^{a}$ Yasuhiro Nishiyama, ${ }^{\mathrm{a}}$ \\ Kiyomi Kakiuchi, ${ }^{\mathrm{a}}$ Levent Artok $^{\mathrm{b}}$ \\ a Graduate School of Materials Science, Nara Institute of Science and Technology (NAIST), Ikoma, Nara 630-0192, Japan \\ Fax+81(743)726081; E-mail: morimoto@ms.naist.jp \\ b Department of Chemistry, Faculty of Science, Izmir Institute of Technology, Urla 35430, Izmir, Turkey \\ Received: 27.01.2014; Accepted after revision: 28.02.2014
}

\begin{abstract}
The rhodium(I)-catalyzed reaction of alkynes with arylboronic acids in the presence of formaldehyde resulted in a carbon monoxide gas-free carbonylative arylation to yield $\alpha, \beta$-enones. The simultaneous loading of phosphine-ligated and phosphine-free rhodium(I) complexes is required for efficient catalysis, which catalyze the abstraction of a carbonyl moiety from formaldehyde (decarbonylation) and its subsequent introduction into the substrate (carbonylation), respectively.
\end{abstract}

Key words: carbonylation, arylation, rhodium, formaldehyde, alkynes

Transition-metal-catalyzed carbonylation represents an essential type of reaction leading to the efficient preparation of a wide class of carbonyl-containing compounds. ${ }^{1}$ Considerable attempts have been made to simplify the experimental manipulation and to exploit novel carbonylative transformation, that is, the carbon monoxide gas-free carbonylation methods using carbonyl donors, ${ }^{2}$ such as formic acid, ${ }^{3 \mathrm{a}}$ formates,${ }^{3 \mathrm{~b}}$ formamides,${ }^{3 \mathrm{c}}$ chloroform, ${ }^{3 \mathrm{~d}}$ alcohols, ${ }^{3 \mathrm{e}}$ acid halides, ${ }^{3 \mathrm{f}}$ and metal carbonyls. ${ }^{3 \mathrm{~g}} \mathrm{We}^{4}$ and other groups ${ }^{5}$ also recently reported on the development of a convenient carbonylation protocol using aldehydes as a carbonyl source. In the methodology, the rhodium(I)catalyzed decarbonylation of an aldehyde is the essential key process as a carbonyl donor. However, a catalyst that is effective for the targeted carbonylation process is not always consistent with that for the decarbonylation process, which generally proceeds in the presence of a rhodium(I)-phosphine complex.

Among the examples we developed, the rhodium(I)-catalyzed cyclocarbonylation reactions of alkynes with arylboronic acids corresponds to such a situation (Scheme 1, a). ${ }^{4 \mathrm{~d}}$ The original reaction, in which carbon monoxide is used, is catalyzed by a phosphine-free rhodium(I) complex. ${ }^{6}$ In this case, we achieved a similar transformation using formaldehyde instead of carbon monoxide by controlling the amount of added phosphine ligand so that rhodium complexes both with and without phosphine ligand are present, thus permitting both decarbonylation and carbonylation to proceed in a single catalyst system. During the study of the carbon monoxide gas-free carbonylation

SYNLETT 2014, 25, 1155-1159

Advanced online publication: 27.03.2014

DOI: 10.1055/s-0033-1341046; Art ID: ST-2014-U0080-L

(C) Georg Thieme Verlag Stuttgart · New York catalysis involving phosphine-ligated and phosphine-free rhodium catalysts, we found that the catalyst system is applicable for another carbonylation reaction catalyzed by a phosphine-free rhodium(I) complex. We report herein on the formaldehyde-substituted carbonylation reactions of alkynes with arylboronic acids using such a catalyst system, resulting in a carbonylative arylation to give enone derivatives (Scheme 1, b). This can substitute for the conventional phosphine-free rhodium(I)-catalyzed reaction and avoids the direct use of carbon monoxide.

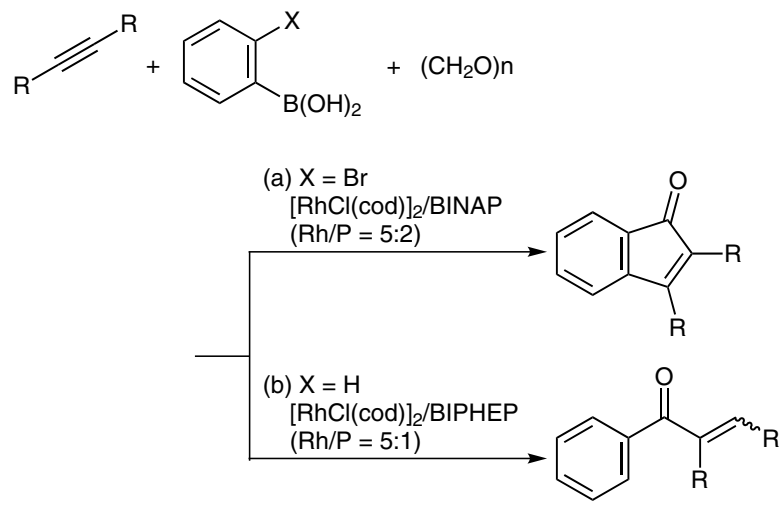

Scheme 1 Phosphine-free and ligated dual Rh-catalyzed carbonylation reactions using formaldehyde as the $\mathrm{CO}$ source

Our previous reports revealed that a phosphine-free rhodium(I) catalyst such as $\left[\mathrm{RhCl}\left(\mathrm{C}_{2} \mathrm{H}_{4}\right)_{2}\right]_{2}$ is effective for the carbonylative arylation of alkynes with arylboronic acids using carbon monoxide. ${ }^{7}$ We examined the reaction of diphenylacetylene (1a), phenylboronic acid (2a), and paraformaldehyde under catalytic conditions consisting of 5 $\mathrm{mol} \%$ of $[\mathrm{RhCl}(\mathrm{cod})]_{2}$ and $2 \mathrm{~mol} \%$ of BIPHEP, ${ }^{8}$ which are similar to the catalytic conditions used in the abovementioned reaction. ${ }^{4 \mathrm{~d}}$ Consequently, the reaction resulted in a carbon monoxide gas-free carbonylative arylation reaction, with the production of enones $3 \mathbf{a a}$ in $46 \%$ yield as a mixture of $E$ - and $Z$-isomers in a ratio of $37: 63$, along with a $9 \%$ yield of the hydroarylation product 4 aa (Table 1 , entry 3$)$. The geometry of $(E)$ - and $(Z)$-3aa was assigned by X-ray crystallographic analysis, and the ratio of the forms of 3aa was determined by ${ }^{1} \mathrm{H}$ NMR analysis. We subsequently examined different amounts of added BIPHEP from $0 \mathrm{~mol} \%$ to $10 \mathrm{~mol} \%$ to $5 \mathrm{~mol} \%$ $[\mathrm{RhCl}(\mathrm{cod})]_{2}$ (Table 1, entries 1-5). The use of $1 \mathrm{~mol} \%$ of 
BIPHEP resulted in the best result, $62 \%$ yield of 3 aa. The hydroarylation product 4aa was mainly obtained when BIPHEP was absent (Table 1, entry 1). When $10 \mathrm{~mol} \%$ of BIPHEP, which accounts for all of the loaded rhodium, was added, 3aa was produced in much lower yield (Table 1 , entry 5). These results imply that $[\mathrm{RhCl}(\mathrm{BIPHEP})]_{2}$ and $[\mathrm{RhCl}(\mathrm{cod})]_{2}$ are predominantly involved in the decarbonylation and carbonylative arylation processes, respectively.

Table 1 Effect of BIPHEP in Rhodium(I)-Catalyzed Reaction of 1a with 2a Using Paraformaldehyde as a CO Source ${ }^{\mathrm{a}}$

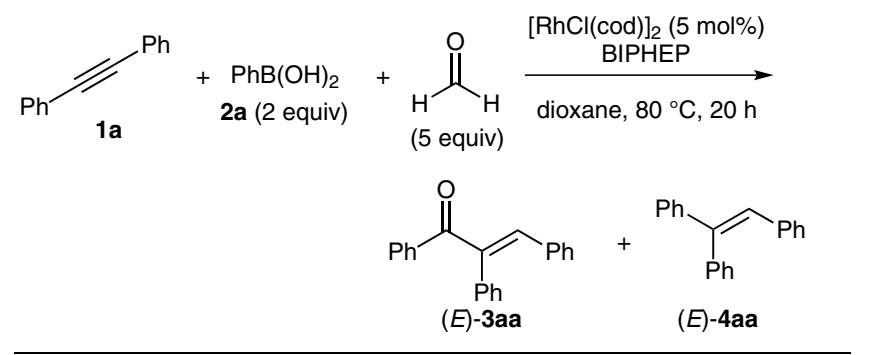

\begin{tabular}{llll}
\hline Entry & BIPHEP $(\mathrm{mol} \%)$ & $\begin{array}{l}\text { Yield }(\%)^{\mathrm{b}} \\
\text { 3aa }(E / Z)^{\mathrm{c}}\end{array}$ & $(E)$-4aa \\
\hline 1 & 0 & $32(39: 61)$ & 56 \\
2 & 1 & $62(32: 68)$ & 7 \\
3 & 2 & $46(37: 63)$ & 9 \\
4 & 5 & $27(35: 65)$ & 4 \\
5 & 10 & $4(57: 43)$ & 1 \\
\hline
\end{tabular}

${ }^{\text {a }}$ Reaction conditions: 1a $(1 \mathrm{mmol}), \mathbf{2 a}(2 \mathrm{mmol})$, paraformaldehyde (5 mmol), $[\mathrm{RhCl}(\mathrm{cod})]_{2}(5 \mathrm{~mol} \%)$ in dioxane $(1 \mathrm{~mL})$ at $80{ }^{\circ} \mathrm{C}$ for $20 \mathrm{~h}$. ${ }^{\mathrm{b}}$ Isolated yield.

${ }^{\mathrm{c}}$ Determined by ${ }^{1} \mathrm{H}$ NMR.

Results using various phosphines as a ligand to the rhodium catalyst in the carbonylative arylation of $\mathbf{1} \mathbf{a}$ with $\mathbf{2 a}$ are summarized in Table 2. With the addition of a monodentate phosphine, such as triphenylphosphine, 3aa was obtained in low yield of $26 \%$, along with the hydroarylated product $(E)-\mathbf{4 a a}$ in $54 \%$ yield (Table 2, entry 1 ). Among other bidentate ligands tested (Table 2, entries 26), BIPHEP gave the best result as shown in Table 1, entry 2 . The standard catalytic conditions for the reaction were determined to be $5 \mathrm{~mol} \%$ of $[\mathrm{RhCl}(\mathrm{cod})]_{2}$ and $1 \mathrm{~mol} \%$ of BIPHEP.

With the above optimized conditions in hand, we next investigated the effect of the electronic nature of the substituent on the aromatic ring of arylboronic acids $\mathbf{2}$ on the carbonylative arylation of diphenylacetylene (1a). Reactions with arylboronic acids having an electron-donating group at the para position of the aromatic ring, such as 4-methoxyphenylboronic acid (2b) and 4-methylphenylboronic acid (2c), yielded the corresponding carbonylated products $\mathbf{3 a b}$ and $\mathbf{3 a c}$ in $77 \%$ and $70 \%$ yields as a mixture of $E$ - and $Z$-isomers, along with a trace and a $2 \%$ yield of the hydroarylated (noncarbonylated) products $\mathbf{4 a b}$ and
Table 2 Screening of Phosphine Ligands in Synthesis of $\mathbf{3} \mathbf{a a}^{\mathrm{a}}$

\begin{tabular}{llll}
\hline Entry & Phosphine & $\begin{array}{l}\text { Yield }(\%)^{\mathrm{b}} \\
\text { 3aa }(E / Z)^{\mathrm{c}}\end{array}$ & $(E)$-4aa \\
\hline 1 & $2 \mathrm{Ph}_{3} \mathrm{P}$ & $26(37: 63)$ & 54 \\
2 & Xantphos & $12(35: 65)$ & 58 \\
3 & dppe & $44(37: 63)$ & 21 \\
4 & dppp & $39(35: 65)$ & 18 \\
5 & dppf & $29(37: 63)$ & 48 \\
6 & BINAP & $52(46: 54)$ & 11 \\
\hline
\end{tabular}

${ }^{a}$ Reaction conditions: 1 ( $\left.1 \mathrm{mmol}\right), \mathbf{2}(2 \mathrm{mmol})$, paraformaldehyde (5 $\mathrm{mmol}),[\mathrm{RhCl}(\mathrm{cod})]_{2}(5 \mathrm{~mol} \%)$, phosphine as ligand ( $\left.1 \mathrm{~mol} \%\right)$ except for $\mathrm{Ph}_{3} \mathrm{P}(2 \mathrm{~mol} \%)$ in dioxane $(1 \mathrm{~mL})$ at $80{ }^{\circ} \mathrm{C}$ for $20 \mathrm{~h}$.

${ }^{\mathrm{b}}$ Isolated yield.

${ }^{\mathrm{c}}$ Determined by ${ }^{1} \mathrm{H}$ NMR.

4ac, respectively (Table 3, entries 1 and 2). On the other hand, the introduction of an electron-withdrawing group (2d 4-Cl; 2e 4-F $\mathrm{F}_{3} \mathrm{C}$ ) decreased the yields of the carbonylated products 3 ad (53\%) and 3ae (45\%), while the yields of noncarbonylated products $4 \mathbf{a d}$ and $4 \mathbf{a e}$ were increased (Table 3, entries 4 and 5). Generally, the more electrondonating $\mathrm{R}$ group becomes, the more smoothly the migratory insertion of the $\mathrm{R}$ group onto the carbonyl ligand takes place to shift the equilibrium between acyl-metal (RCOM) and alkyl-metal-carbonyl (RMCO, Scheme 2) to the generation of the RCOM species, due to the thermodynamic strength of the RM bond. ${ }^{9}$ In the present cases, the former analogue would be involved in the formation of the carbonylated products $\mathbf{3}$, and the latter in that of noncarbonylated products $\mathbf{4}$. Thus, as the electron-donating strength of the substituent on the aromatic ring of $\mathrm{ArB}(\mathrm{OH})_{2}$ decreases, the yields of enones $\mathbf{3}$ decrease and those of $\mathbf{4}$ increase.

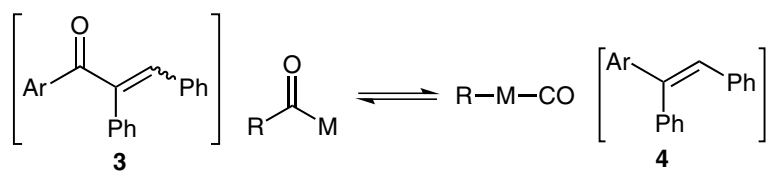

Scheme 2 Equilibrium between RCOM and RMCO

As the position of the substituent was changed from para to meta and ortho, the yield of the carbonylative arylation products 3ab, 3af, and 3ag decreased, and that of the hydroarylation products 4ab, 4af, and 4ag increased (Table 3 , entries 1,6 , and 7). The position of the substituent has almost no impact on the ratio of the $E$ - and $Z$-somers of 3ab, 3af, and 3ag.

The applicability of other alkynes under the present carbonylation conditions was examined (Table 4). In most cases, the present method leads to the efficient formation of products even without the use of trifluoroacetic acid as an additive, which is need for the reaction using carbon monoxide. ${ }^{7}$ Reactions of diphenylacetylene derivatives 
Table 3 Reactions of 1a with Various 2 Using Paraformaldehyde as a CO Source ${ }^{\mathrm{a}}$

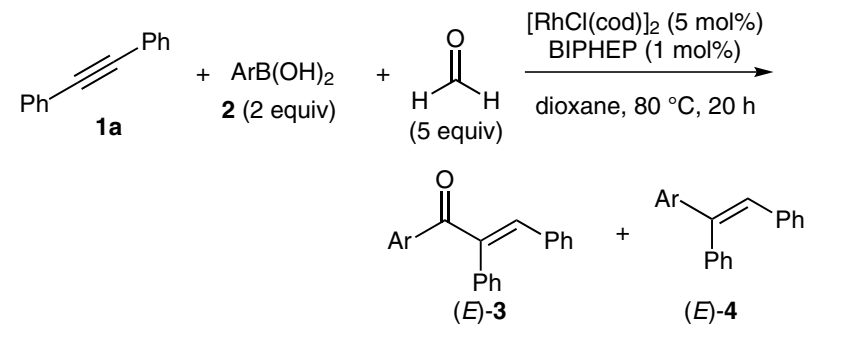

\begin{tabular}{llll}
\hline Entry & Ar 2 & $\begin{array}{l}\text { Yield (\%) } \\
\text { 3 }(E / Z)^{\mathrm{c}}\end{array}$ & $(E)-\mathbf{4}$ \\
\hline 1 & $4-\mathrm{MeOC}_{6} \mathrm{H}_{4}$ & 3ab 77 (26:74) & 4ab trace \\
2 & $4-\mathrm{MeC}_{6} \mathrm{H}_{4}$ & 3ac 70 (27:73) & 4ac 2 \\
3 & $\mathrm{H}$ & 3aa 62 (32:68) & 4aa 7 \\
4 & $4-\mathrm{ClC}_{6} \mathrm{H}_{4}$ & 3ad 53 (35:65) & 4ad 9 \\
5 & $4-\mathrm{F}_{3} \mathrm{CC}_{6} \mathrm{H}_{4}$ & 3ae 45 (41:59) & 4ae 12 \\
6 & $3-\mathrm{MeOC}_{6} \mathrm{H}_{4}$ & 3af 61 (28:72) & 4af 2 \\
7 & 2- $\mathrm{MeOC}_{6} \mathrm{H}_{4}$ & 3ag 23 (30:70) & 4ag 18 \\
\hline
\end{tabular}

a Reaction conditions: 1 (1 mmol), 2 (2 mmol), paraformaldehyde (5 $\mathrm{mmol}),[\mathrm{RhCl}(\mathrm{cod})]_{2}(5 \mathrm{~mol} \%)$, BIPHEP $(1 \mathrm{~mol} \%)$ in dioxane $(1 \mathrm{~mL})$ at $80{ }^{\circ} \mathrm{C}$ for $20 \mathrm{~h}$.

${ }^{\mathrm{b}}$ Isolated yield.

${ }^{\mathrm{c}}$ Determined by ${ }^{1} \mathrm{H}$ NMR.

$\mathbf{1 b}$ and 1c with 4- $\mathrm{MeOC}_{6} \mathrm{H}_{4} \mathrm{~B}(\mathrm{OH})_{2}(\mathbf{2 b})$ gave the corresponding enones $\mathbf{3 b b}$ and $\mathbf{3 c b}$ in $60 \%(E / Z=32: 68)$ and $54 \%(E / Z=25: 75)$ yields, respectively (Table 4 , entries 1 and 2). An alkyl substituent ( $n$-Pr) at the terminus of the alkyne was tolerant in the present reaction, although the addition of two equivalents of trifluoroacetic acid was required (Table 4, entry 3). ${ }^{10}$ For unsymmetrical alkynes having phenyl and alkyl groups (1e and $\mathbf{1 f}$ ), the reactions proceeded somewhat regioselectively to give predominantly the enones $\mathbf{3 e b}$ and $\mathbf{3 f b}$, respectively, in both of which phenyl group is located at the $\beta$-position of the aroyl groups (Table 4, entries 4 and 5).

In order to ascertain the origin of the hydrogen at the $\beta$-position of the enones 3aa, we carried out some deuteriumlabeling experiments. Initially, the reaction of diphenylacetylene (1a) with phenylboronic acid (2a) in the presence of paraformaldehyde- $d_{2}\left[\left(\mathrm{CD}_{2} \mathrm{O}\right)_{\mathrm{n}}\right]$ was exposed to the above reaction conditions to give $\mathbf{3}$ aa as a mixture of $E$ - and $Z$-isomers in a ratio of 34:66. A ${ }^{1} \mathrm{H}$ NMR analysis revealed that less than $2 \%$ of deuterium was incorporated into the $\beta$-position of the enones 3aa (Scheme 3). On the other hand, when 2,4,6-triphenylboroxine $\left[(\mathrm{PhBO})_{3}\right]$ and $\mathrm{D}_{2} \mathrm{O}$, which should generate the deuterated phenylboronic acid $\left(\mathrm{PhB}(\mathrm{OD})_{2}\right)$ in situ, was used instead of phenylboronic acid (2a), $76 \%$ and $87 \% \mathrm{D}$ were incorporated into $\beta$-position of $(E)$ - and $(Z)-3 \mathbf{a a} .{ }^{11}$ These results indicate that the origin of the hydrogen is the acidic proton of phenylboronic acid.
Table 4 Reactions of Various Alkynes 1 with 2b Using Paraformaldehyde as a CO Source ${ }^{\text {a }}$

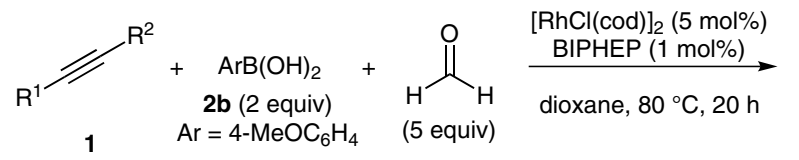<smiles>[R]C=C([R7])C(=O)[18F]</smiles>

$(E)-3$

$(E)-\mathbf{3}^{\prime}$

\begin{tabular}{lllll}
\hline Entry & $\mathbf{1}$ & $\mathrm{R}^{1}$ & $\mathrm{R}^{2}$ & $\begin{array}{l}\text { Yield (\%) } \\
\mathbf{3}(E / Z)\end{array}$ \\
\hline 1 & $\mathbf{1 b}$ & $4-\mathrm{MeOC}_{6} \mathrm{H}_{4}$ & & $\mathbf{3 b b} 60(32: 68)^{\mathrm{c}}$ \\
2 & $\mathbf{1 c}$ & $4-\mathrm{F}_{3} \mathrm{CC}_{6} \mathrm{H}_{4}$ & & $\mathbf{3 c b} 54(25: 75)^{\mathrm{d}}$ \\
$3^{\text {e }}$ & $\mathbf{1 d}$ & $n-\mathrm{Pr}$ & & $\mathbf{3 d b} 41(93: 7)^{\mathrm{d}}$ \\
4 & $\mathbf{1 e}$ & $\mathrm{Me}$ & $\mathrm{Ph}$ & $\mathbf{3 e b} 42(80: 20)^{\mathrm{c}}$ \\
& & & & $\mathbf{3 e b}^{\prime} 15(37: 63)^{\mathrm{c}}$ \\
5 & $\mathbf{1 f}$ & $n-\mathrm{Bu}$ & $\mathrm{Ph}$ & $\mathbf{3 f b} 42(75: 25)^{\mathrm{c}}$ \\
& & & & $\mathbf{3 f b} 22(34: 66)^{\mathrm{c}}$ \\
\hline
\end{tabular}

${ }^{\text {a }}$ Reaction conditions: 1 (1 mmol), 2 (2 mmol), paraformaldehyde (5 $\mathrm{mmol}),[\mathrm{RhCl}(\mathrm{cod})]_{2}(5 \mathrm{~mol} \%)$, BIPHEP $(1 \mathrm{~mol} \%)$ in dioxane $(1 \mathrm{~mL})$ at $80{ }^{\circ} \mathrm{C}$ for $20 \mathrm{~h}$.

${ }^{\mathrm{b}}$ Isolated yield.

${ }^{\mathrm{c}}$ Determined by ${ }^{1} \mathrm{H}$ NMR

${ }^{\mathrm{d}}$ Ratios of isolated products.

e 2 equiv of TFA were added.

A possible reaction pathway for the present reaction is shown in Scheme 4. As in our previous report, ${ }^{4 \mathrm{~d}}$ the addition of BIPHEP, the amount of which cannot account for all of the loaded rhodium metal, leads to the partial formation of a RhBIPHEP species, probably [RhCl(BIPHEP) $]_{2}$, along with the intact $[\mathrm{RhCl}(\mathrm{cod})]_{2}$. The former BIPHEPligated rhodium(I) species mainly decarbonylates formaldehyde to generate the carbonyl unit and hydrogen, while the latter predominantly catalyzes the actual carbonylation process. Thus, $\mathrm{RhOH}(\mathbf{A})$ generated in situ from $\mathrm{RhCl}$ and $\mathrm{H}_{2} \mathrm{O}$ is transmetalated with $\mathrm{PhB}(\mathrm{OH})_{2}$ to gener-

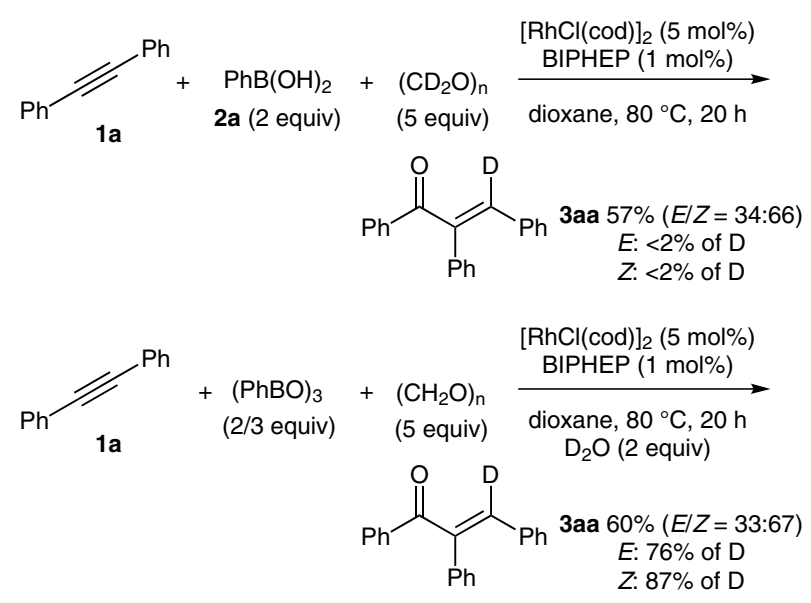

Scheme 3 Deuterium-labelling experiments 
ate $\mathrm{RhPh}(\mathbf{B})$. The carbonyl moiety from the decarbonylation process is transferred to $\mathbf{B}$, followed by the insertion of the $\mathrm{Rh}-\mathrm{C}$ bond in $\mathbf{C}$ to yield RhCOPh (D). The subsequent aroylrhodation to an alkyne $\mathbf{1}$ in a syn manner, followed by the protonation of the formed vinylrhodium $\mathbf{E}$, produces the primary product $(E)-\mathbf{3 a a}$, along with the regeneration of A. $(E)$-3aa isomerizes to give an equilibrium mixture of $(E)$ - and (Z)-3aa under the rhodiumcatalytic conditions in the presence of an acidic arylboronic acid. ${ }^{12,13}$

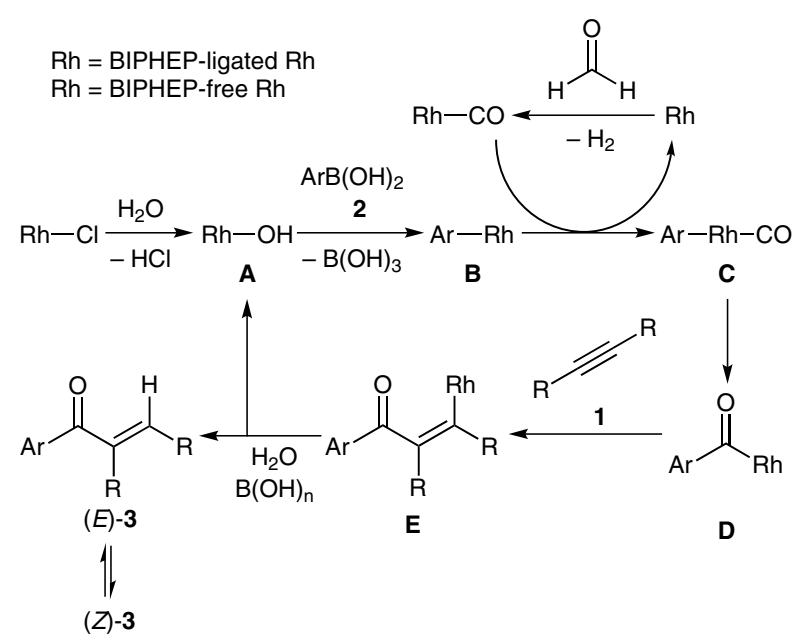

Scheme 4 Possible reaction pathway

In conclusion, we report here on the rhodium(I)-catalyzed carbonylative arylation of alkynes with various arylboronic acids in the presence of formaldehyde as a carbonyl source, resulting in a carbon monoxide gas-free reaction, affording enones. The addition of BIPHEP, the amount of which must not account for all the total phosphine-free rhodium complex $[\mathrm{RhCl}(\mathrm{cod})]_{2}$ leads to the partial formation of phosphine-ligated complex $[\mathrm{RhCl}(\mathrm{BIPHEP})]_{2}$ along with intact $[\mathrm{RhCl}(\mathrm{cod})]_{2}$, which are mainly involved in the decarbonylation of formaldehyde to produce a carbonyl moiety and the subsequent carbonylative arylation of alkynes with arylboronic acids using the resulting carbonyl moiety, respectively, leading to an efficient carbonylative arylation to produce $\alpha, \beta$-enones.

In a $10 \mathrm{~mL}$ screw-capped vial were placed $[\mathrm{RhCl}(\operatorname{cod})]_{2}(24.6 \mathrm{mg}$, $0.05 \mathrm{mmol})$, BIPHEP (5.3 mg, $0.01 \mathrm{mmol})$, alkyne 1 (1 mmol), arylboronic acid $2(2 \mathrm{mmol})$, paraformaldehyde $(150.2 \mathrm{mg}, 5 \mathrm{mmol})$, and 1,4-dioxane $(1 \mathrm{~mL})$. The mixture was degassed by three freezepump-thaw cycles and then sealed under $\mathrm{N}_{2}$. The mixture was stirred at $80^{\circ} \mathrm{C}$ for $20 \mathrm{~h}$, cooled to r.t. and then concentrated in vacuo. The residue was purified by flash chromatography on silica gel.

\section{Acknowledgment}

This research was supported by a Grant-in-Aid for Scientific Research on Innovative Areas 'Molecular Activation Directed toward Straightforward Synthesis' from the Ministry of Education, Culture, Sports, Science and Technology, Japan. We also thank Ms. Yuriko Nishiyama, Ms. Yoshiko Nishikawa, and Mr. Shouhei Katao for assistance in obtaining HRMS and X-ray crystallographic data.
Supporting Information for this article is available online at http://www.thieme-connect.com/ejournals/toc/synlett.

\section{References and Notes}

(1) (a) Kollár, L. Modern Carbonylation Methods; Wiley-VCH: Weinheim, 2008. (b) Beller, M. Catalytic Carbonylation Reactions; Springer: Berlin, 2006.

(2) For a review, see: Morimoto, T.; Kakiuchi, K. Angew. Chem. Int. Ed. 2004, 43, 5580.

(3) For recent papers, see: (a) Brancour, C.; Fukuyama, T.; Mukai, Y.; Skrydstrup, T.; Ryu, I. Org. Lett. 2013, 15, 2794. (b) Ueda, T.; Konishi, H.; Manabe, K. Org. Lett. 2012, 14, 3100. (c) Ju, J.; Jeong, M.; Moon, J.; Jung, H. M.; Lee, S. Org. Lett. 2007, 9, 4615. (d) Grushin, V. V.; Alper, H. Organometallics 1993, 12, 3846. (e) Park, J. H.; Cho, Y.; Chung, Y. K. Angew. Chem. Int. Ed. 2010, 49, 5138. (f) Bjerglund, K.; Lindhardt, A. T.; Skrydstrup, T. J. Org. Chem. 2013, 78, 6112. (g) Nordeman, P.; Odell, L. R.; Larhed, M. J. Org. Chem. 2012, 77, 11393.

(4) For selected papers, see: (a) Ikeda, K.; Morimoto, T.; Tsumagari, T.; Tanimoto, H.; Nishiyama, Y.; Kakiuchi, K. Synlett 2012, 23, 393. (b) Fujioka, M.; Morimoto, T.; Tsumagari, T.; Tanimoto, H.; Nishiyama, Y.; Kakiuchi, K. J. Org. Chem. 2012, 77, 2911. (c) Makado, G.; Morimoto, T.; Sugimoto, Y.; Tsutsumi, K.; Kagawa, N.; Kakiuchi, K. Adv. Synth. Catal. 2010, 352, 299. (d) Morimoto, T.; Yamasaki, K.; Hirano, A.; Tsutsumi, K.; Kagawa, N.; Kakiuchi, K.; Harada, Y.; Fukumoto, Y.; Chatani, N.; Nishioka, T. Org. Lett. 2009, 11, 1777.

(5) For recent papers, see: (a) Lee, H. W.; Lee, L. N.; Chan, A. S. C.; Kwong, F. Y. Eur. J. Org. Chem. 2008, 3403.

(b) Shibata, T.; Toshida, N.; Yamasaki, M.; Maekawa, S.; Takagi, K. Tetrahedron 2005, 61, 9974. (c) Jeong, N.; Kim, D. H.; Choi, J. H. Chem. Commun. 2004, 1134.

(6) Harada, Y.; Nakanishi, J.; Fujihara, H.; Tobisu, M.; Fukumoto, Y.; Chatani, N. J. Am. Chem. Soc. 2007, 129, 5766.

(7) (a) Artok, L.; Kuş, M.; Aksın-Artok, Ö.; Dege, F. N.; Özkılınç, F. Y. Tetrahedron 2009, 65, 9125. (b) Kuş, M.; Artok, Ö. A.; Ziyanak, F.; Artok, L. Synlett 2008, 2587.

(8) Abbreviations: BIPHEP $=2,2^{\prime}$-bis(diphenylphosphino)-1,1'biphenyl; Xantphos = 9,9-dimethyl-4,5-bis(diphenylphosphino)xanthene; dppe $=1,2$-bis(diphenylphosphino)ethane; dppp = 1,3-bis(diphenylphosphino)propane; dppf = $1,1^{\prime}$-bis(diphenylphosphino)ferrocene; BINAP $=2,2^{\prime}=$ bis(diphenylphosphino)-1,1'-binaphthyl.

(9) (a) Fristrup, P.; Kreis, M.; Palmelund, A.; Norrby, P.-O.; Madsen, R. J. Am. Chem. Soc. 2008, 130, 5206. (b) Calderazzo, F. Angew. Chem., Int. Ed. Engl. 1977, 16, 299.

(10) The role of TFA is, at present, unclear. We postulate the following two possibilities: (i) it promotes the generation of free formaldehyde from paraformaldehyde, and (ii) it accelerates the protonation of the vinylrhodium species $\mathbf{E}$ to give the product.

(11) The fact that the deuteration of the $\beta$-position of the enones 3aa does not reach $99 \%$ is due to $\mathrm{H}-\mathrm{D}$ exchange via 1,3 - and 1,4-shift of the rhodium in the intermediate $\mathbf{E}$ to other $\mathrm{Ph}$ rings at $\beta$-position: (a) Sasaki, K.; Nishimura, T.; Shintani, R.; Kantchev, E. A. B.; Hayashi, T. Chem. Sci. 2012, 3, 1278. (b) Hayashi, T.; Inoue, K.; Taniguchi, N.; Ogasawara, M. J. Am. Chem. Soc. 2001, 123, 9918; indeed, the H integration of the aromatic ring is lower than that of $\mathbf{3 a a}$ from the reaction of 1a with $\mathrm{PhB}(\mathrm{OH})_{2}$ using $\left(\mathrm{CH}_{2} \mathrm{O}\right)_{\mathrm{n}}$.

(12) Even when $\mathrm{C}_{6} \mathrm{~F}_{5} \mathrm{CHO}$, which should not generate a RhH species, was used as a carbonyl source, the reaction gave 
unselectively a mixture of $(E)$ - and $(Z)-3$ aa in $2 \%$ yield $(E / Z$ $=37: 63$ ). We have observed the similar result when carbon monoxide was used as a carbonyl source (ref. 7).

(13) Each of the $(E)$ - and (Z)-3aa isolated in pure form was introduced into reactions of 4-methoxyphenylboronic acid (2b) and alkyne 1a under the standard conditions. Each reaction gave the product $\mathbf{3 a b}$ in almost the same yield. It is noteworthy that 3 aa was recovered in the same $E / Z$ ratio $(E / Z=32: 68)$ in each case and that they are also the same as that of the reaction in Table 1 , entry 2 . Thus, $E / Z$ isomerization of the products 3 takes place readily under the present conditions. Moreover, the reactions of $(E)$ - and $(Z)$ 3aa in the presence of a catalytic amount of

$\mathrm{RhH}(\mathrm{CO})\left(\mathrm{PPh}_{3}\right)_{3}$ gave a $E / Z$ mixture of 3aa quantitatively in a similar ratio, $E / Z=36: 64$ and 34:66, respectively.

Therefore, we currently do not eliminate the possibility that $E / Z$ isomerization proceeds via the hydrorhodation of $\mathrm{RhH}$, generated from $\mathrm{Rh}$ and hydrogen (decarbonylation counterpart), to the primary product $(E)$-enone and the subsequent rotation of the $\mathrm{C}-\mathrm{C}$ single bond, followed by the $\beta$-H elimination to $(Z)$-enone. See the Supporting Information. 
Copyright of Synlett is the property of Georg Thieme Verlag Stuttgart and its content may not be copied or emailed to multiple sites or posted to a listserv without the copyright holder's express written permission. However, users may print, download, or email articles for individual use. 